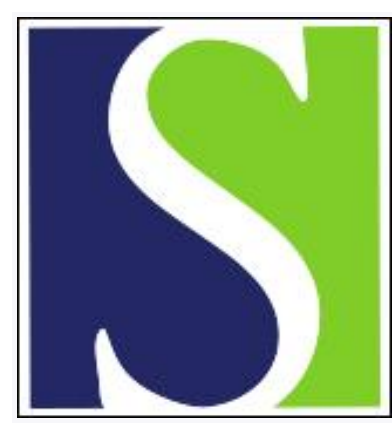

Scand J Work Environ Health 1989;15(5):313-318

https://doi.org/10.5271/sjweh.1845

Issue date: Oct 1989

Aplastic anemia, leukemia and other cancer mortality in a cohort of shoe workers exposed to benzene.

by Paci E, Buiatti E, Seniori Costantini AS, Miligi L, Pucci N, Scarpelli A, Petrioli G, Simonato L, Winkelmann R, Kaldor JM

Affiliation: Centre for Study and Prevention of Cancer, Florence, Italy.

This article in PubMed: www.ncbi.nlm.nih.gov/pubmed/2799316

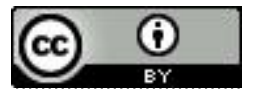




\title{
Aplastic anemia, leukemia and other cancer mortality in a cohort of shoe workers exposed to benzene
}

\author{
by Eugenio Paci, MD, ${ }^{1}$ Eva Buiatti, MD, ${ }^{1}$ Adele Seniori Costantini, MD, ${ }^{1}$ Lucia Miligi, MSc, ${ }^{1}$ \\ Neri Pucci, MD, ${ }^{1}$ Annnarosa Scarpelli, MSc, ${ }^{2}$ Giuseppe Petrioli, MD, ${ }^{2}$ Lorenzo Simonato, MD, ${ }^{3}$ \\ Regina Winkelmann, MSc, ${ }^{3}$ John M Kaldor, $\mathrm{PhD}^{3}$
}

\begin{abstract}
PACI E, BUIATTI E, SENIORI COSTANTINI A, MILIGI L, PUCCI N, SCARPELli A, PETRIOLI G, SIMONATO L, WINKELMANN R, KALDOR JM. Aplastic anemia, leukemia and other cancer mortality in a cohort of shoe workers exposed to benzene. Scand J Work Environ Health 1989;15:313-318. Benzene is a well documented carcinogen for the hematic and lymphopoietic system, and experimental research confirms its carcinogenicity for tumors of other sites. This report presents the results of a historical cohort study in a shoe manufacturing plant in Florence where cases of aplastic anemia and leukemia were reported in the 1960s. A total of 1008 men and 1005 women were considered eligible members of the cohort. For total mortality, comparing the rates of the cohort with the national rates, the standardized mortality ratio (SMR) was 79 for the women and 95 for the men. For the men excesses of risk for aplastic anemia [SMR 1566; $95 \%$ confidence interval $(95 \% \mathrm{CI}) 547-3264$ ] and leukemia (SMR 400, $95 \% \mathrm{Cl}$ $146-870$ ) were observed. The increased risk occurred among workers first employed during the period in which benzene was used, but the expected number of cases in the subsequent period was too small to evaluate whether any reduction in risk had occurred. No increasing pattern with duration of employment was discernible.
\end{abstract}

Key terms: epidemiology, solvents.

One of the monographs of the International Agency for Research on Cancer (IARC) has evaluated as "sufficient" the epidemiologic evidence on the carcinogenicity of benzene (1). The observed toxic and carcinogenic effects of exposure were mainly related to the hematopoietic system, including pancytopenia and leukemia, mostly of the acute myeloid type. A major contribution to the evidence was from case reports of aplastic anemia and leukemia among workers who were occupationally exposed to benzene in Milan and Pavia (2) and from case series from Turkey (3). Prominent among the industries involved was shoe manufacturing, in which benzene was widely used as a solvent for glues.

The IARC monograph on benzene (1) reported that there was no clear evidence of an increased risk for other malignancies among exposed humans. However, experimental data have shown evidence that benzene is a multipotential carcinogen in rats $(4,5)$. An IARC monograph on shoe workers (6) reported an excess of risk for nasal adenocarcinoma and suggested an association with bladder cancer. Some other cancer sites were also considered in the monograph, but for none of these was the evidence considered to support a clear causal relationship.

\footnotetext{
1 Centre for Study and Prevention of Cancer, Florence, Italy. 2 Occupational Service, USL 10/E, Florence, Italy.

${ }^{3}$ International Agency for Research on Cancer, Lyon, France.
}

Reprint requests to: Dr E Paci, CSPO, V le A Volta 171, I-50131 Firenze, Italy.
In Florence (Tuscany), shoe manufacturing is a traditional industrial activity and, following the reports on leukemia, an increased effort has been made to monitor the exposure levels and health status of shoe workers. At the end of 1963 , a national law limited the use of benzene in shoe glues to less than $2 \%$ of the total solvent.

Although there have been reports of leukemia among shoe workers in Florence and other Italian cities, no epidemiologic study has ever been carried out on this subject.

In the present paper, we report on a historical cohort study of workers employed in the largest shoe manufacturing plant in Florence. It was already known that during the 1960 s six deaths from aplastic anemia or leukemia had occurred among the workers. The study had the following two goals: (i) to describe aplastic anemia and leukemia mortality among shoe workers during and after the period of benzene exposure and (ii) to evaluate the mortality risk from other neoplasms following exposure to benzene.

\section{Subjects and methods}

The plant

The source of information was the records of the largest shoe manufacturing company in Florence. This company existed prior to the Second World War in four separate locations and in 1954 was consolidated at the present location, where all the work is now carried out. 
The register of employees has always been centralized for the entire company so that now workers cannot be identified according to specific buildings in which they worked from the beginning of the plant until 1953. From the beginning of 1954 on, the main activities have all been carried out on one floor (the ground floor) of the main building.

Between the period 1961-1962 the main building was completely restructured. During this time, characterized by the highest levels of exposure to benzene, all activities were carried out in two communicating departments. The first consisted of the storerooms and cutting section, while in the second the main shoemaking activity was performed.

At the end of 1961, the building was considerably extended, and since then the activities have been subdivided as follows: ground (or first) floor: shoemaking department, consisting of five workshops (about 400 employees), storage department; second floor: finishing department (60 employees); third floor: assembling department (150 employees); fourth floor: cutting department ( 90 employees); fifth floor: offices $(10 \mathrm{em}$ ployees).

Until the renovations at the end of 1961, the only ventilation in the plant was supplied by windows and fans. In April 1962 the installation of mechanical air conditioning and local ventilation systems was completed.

\section{Assessment of benzene exposure}

Original plant production records, factory inspection reports, and information from the glue suppliers were reviewed for this study. In these documents it was reported that in this shoe factory the use of glues containing benzene began between 1950 and 1955, and one report specifically referred to 1953 . This information can be considered reliable because during World War II and immediately afterwards coal-based chemical products such as benzene were not easily available in Italy, and the use of "latexes" in the glues was prevalent.

Data available for the years 1957-1960 (probably a good estimate of the situation from 1953 to 1960 ) show that the three main glues used in shoe manufacturing contained more than $70 \%$ benzene by weight. It was estimated that $20 \mathrm{~g}$ of glue was used for each pair of shoes for a total of 2200 pairs per day, corresponding, on the average, to $42.5 \mathrm{~kg}$ of glue used each day in the plant. The glues were kept in open containers with an opening of $15 \mathrm{~cm}$; only after 1962 were these containers replaced by cans with a small opening (about $8 \mathrm{~cm}$ in diameter).

In 1963, when the law limiting the use of benzene came into effect, the commercial product formula was changed. Hexane became the most important solvent, and the glue contained solvent with less then $2 \%$ benzene. Nevertheless, old products, including those which were benzene-based, were still used until 1964. Glues were primarily used in the shoemaking department, sel- dom in the finishing department, and no use was reported in the cutting and storage departments.

As the main part of the production process occurred on the ground floor, indirect exposure of the workers was possible. Using the plant history, we defined the following four periods of benzene exposure: (i) before 1953, prior to the introduction of benzene (considering the uncertainty of the exposure information, members of the cohort who left the plant before 1953 were classified as "unlikely" to have been exposed); (ii) the subsequent years 1953-1962, which were considered to comprise the high exposure period; (ii) after 1962 until the end of 1964, period of "intermediate" exposure because benzene use was declining substantially; (iv) after 1964, the time of very low levels as a result of the 1963 law. Subjects employed after 1964 were considered unexposed.

\section{Study population}

All individuals ever employed at the plant from 1939 to the end of the study period (31 December 1984) and still employed in or after January 1950 were considered members of the cohort. From the plant register, demographic information and the dates of starting and leaving work in the plant were obtained. The vital status of the cohort members was ascertained through 31 December 1984 from the official register of the municipality of residence. From the same register copies of death certificates were obtained. Causes of death were classified from the death certificates according to the eighth revision of the International Classification of Diseases (ICD) (7) by two doctors, one of whom carries out coding for the Tuscan Mortality Registry. The national Italian mortality rates, specific for cause, age, sex, and calendar period and computed with the use of the mortality data bank of the World Health Organization, were used as reference.

\section{Additional information on cause of death}

For death certificates mentioning leukemia, aplastic anemia, buccal-pharynx neoplasm, or nasal cancer, more-detailed information was sought from other sources, including the records of the main hospital of the town of Florence and previous case reports or casereferent studies carried out in the Florence area.

\section{Analysis}

The statistical analysis was performed with the personyears program (8). We obtained the number of deaths expected in the cohort by multiplying the accumulated person-years by the national reference rates specific for cause, age, sex, and calendar year, and the standardized mortality ratio (SMR) values were calculated. The $95 \%$ confidence interval $(95 \% \mathrm{CI})$ of each SMR was computed on the basis of the Poisson distribution according to Byar's formula (9). 
An analysis by duration of exposure and time since the date of first exposure was carried out for the subjects who worked in 1953-1964. Three categories of duration of exposure were considered, ie, $<1$ year, $1-5$ years, and $>5$ years.

\section{Results}

A total of 3104 employees were registered in the factory records from 1 January 1939 to 31 December 1984. Restriction to employment on or after 1 January 1950 left 1008 men and 1005 women in the study cohort. Table 1 shows the vital status of the cohort members, whether alive at the end of the study, known to be deceased, or lost to follow-up.

Results were obtained both with the subjects lost to follow-up being considered alive at the last known date and with them considered alive at the end of the study. The difference in person-years was $8.5 \%$ for the men and $11.8 \%$ for the women. The overall results differed little between the two methods, and the first was used in the results that follow.

Observed and expected deaths and the SMR values for selected causes are presented in table 2 for both sexes. Among the women a total of 51 observed deaths occurred versus the 64.3 expected (SMR 79). For four subjects the cause of death was not available. The case defined as a buccal-pharynx neoplasm was a rhinopharyngeal neoplasm (ICD 147). A case of multiple myeloma (ICD 203) was included in the group of "other lymphatic and hematopoietic neoplasms."

One case of aplastic anemia occurred among the women versus 0.2 expected. The woman involved worked in the plant from 1951 to 1962 and died in 1962.

Among the men a total of 171 deaths was observed versus 180.7 expected (SMR 95). The cause of death was unknown for 22 men. Fewer observed than expected deaths for respiratory and digestive tract diseases and accidents occurred among the men. An SMR of 1566 was observed for blood diseases $(95 \% \mathrm{CI}$

Table 1. Study population by vital status.

\begin{tabular}{|c|c|c|c|c|}
\hline \multirow[b]{3}{*}{$\begin{array}{l}\text { Alive at the end of the } \\
\text { study ( } 31 \text { December 1984) }\end{array}$} & \multicolumn{2}{|c|}{ Men } & \multicolumn{2}{|c|}{ Women } \\
\hline & $N$ & $\%$ & $\mathrm{~N}$ & $\%$ \\
\hline & 741 & 73.5 & 825 & 82.1 \\
\hline Deceased & 171 & 17.0 & 51 & 5.1 \\
\hline Lost to follow-up & 96 & 9.5 & 129 & 12.8 \\
\hline $\begin{array}{l}\text { Total number } \\
(1950-1984)\end{array}$ & 1008 & 100 & 1005 & 100 \\
\hline
\end{tabular}

Table 2. Observed $(O)$ and expected $(E)$ causes of death of the shoe factory workers between 1950 and 1984 and the corresponding standardized mortality ratio (SMR) and $95 \%$ confidence interval $(95 \% \mathrm{Cl})$ by sex. The Italian mortality rates of the same period have been used as the reference.

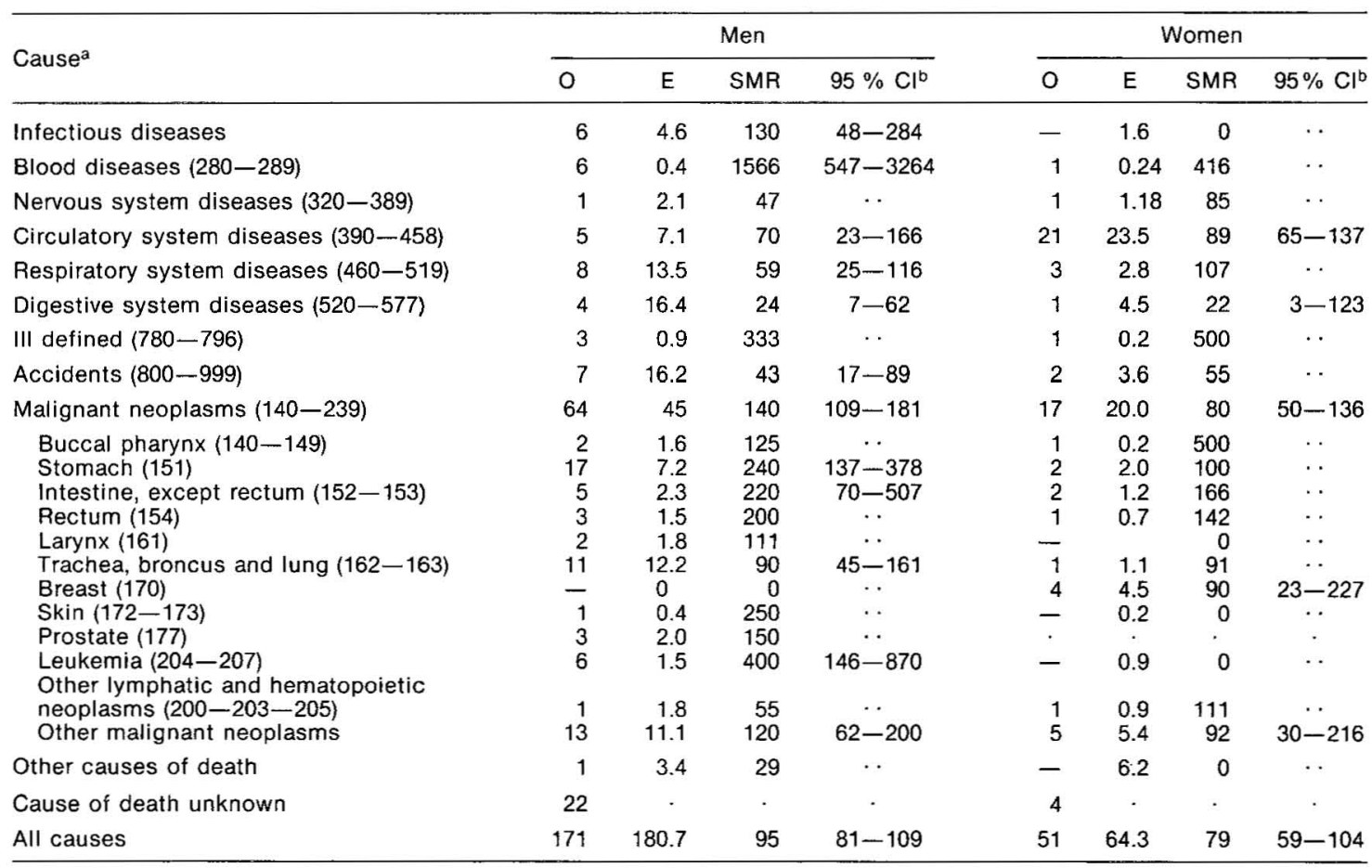

a Code of the International Classification of Diseases, eighth revision, in parentheses.

b $95 \% \mathrm{Cl}$ not calculated for less than four expected or observed deaths. 
Table 3. Observed $(\mathrm{O})$ and expected $(\mathrm{E})$ number of deaths due to leukemia among the male shoe factory workers and the corresponding standardized mortality ratio (SMR) by duration of exposure and by time since first exposure.

\begin{tabular}{|c|c|c|c|c|c|c|c|c|c|}
\hline \multirow{3}{*}{$\begin{array}{l}\text { Time since } \\
\text { first exposure } \\
\text { (years) }\end{array}$} & \multicolumn{8}{|c|}{ Duration of employment in the period 1953-1964 } & \multirow{3}{*}{ SMR } \\
\hline & \multicolumn{2}{|c|}{$<1$ years } & \multicolumn{2}{|c|}{$1-5$ years } & \multicolumn{2}{|c|}{$>5$ years } & \multicolumn{2}{|c|}{ Total } & \\
\hline & 0 & $E$ & 0 & $E$ & $\mathrm{O}$ & $\mathrm{E}$ & 0 & $E$ & \\
\hline $\begin{array}{c}0-4 \\
5-9 \\
10-19 \\
20-29\end{array}$ & $\frac{1}{-}$ & $\begin{array}{l}0.04 \\
0.02 \\
0.04 \\
0.03\end{array}$ & $\frac{-}{1}$ & $\begin{array}{l}0.09 \\
0.06 \\
0.11 \\
0.10\end{array}$ & $\frac{-}{3}$ & $\begin{array}{l}0.00 \\
0.09 \\
0.30 \\
0.33\end{array}$ & $\begin{array}{l}1 \\
1 \\
3 \\
1\end{array}$ & $\begin{array}{l}0.13 \\
0.17 \\
0.45 \\
0.46\end{array}$ & $\begin{array}{l}769 \\
588 \\
666 \\
217\end{array}$ \\
\hline $\begin{array}{l}\text { Total } \\
\text { SMR }\end{array}$ & 1 & $\begin{array}{r}0.13 \\
769\end{array}$ & 2 & $\begin{array}{r}0.36 \\
555\end{array}$ & 3 & $\begin{array}{r}0.72 \\
416\end{array}$ & 6 & $\begin{array}{c}1.21 \\
.\end{array}$ & 495 \\
\hline
\end{tabular}

Table 4. Observed $(\mathrm{O})$ and expected $(\mathrm{E})$ number of deaths among the male shoe factory workers and the corresponding standardized mortality ratio (SMR) by duration of exposure and by time since first exposure.

\begin{tabular}{|c|c|c|c|c|c|c|c|c|c|}
\hline \multirow{3}{*}{$\begin{array}{l}\text { Time since } \\
\text { first exposure } \\
\text { (years) }\end{array}$} & \multicolumn{8}{|c|}{ Duration of employment in the period $1953-1964$} & \multirow{3}{*}{ SMR } \\
\hline & \multicolumn{2}{|c|}{$<1$ years } & \multicolumn{2}{|c|}{$1-5$ years } & \multicolumn{2}{|c|}{$>5$ years } & \multicolumn{2}{|c|}{ Total } & \\
\hline & 0 & $E$ & 0 & $E$ & 0 & $E$ & 0 & $E$ & \\
\hline $0-4$ & 1 & 0.02 & 1 & 0.04 & - & - & 2 & 0.06 & 3333 \\
\hline $5-9$ & - & 0.01 & 1 & 0.03 & 1 & 0.05 & 3 & 0.06 & 5000 \\
\hline $10-19$ & - & 0.01 & - & 0.02 & 1 & 0.08 & 1 & 0.10 & 1000 \\
\hline $20-29$ & - & 0.01 & - & 0.02 & - & 0.06 & - & 0.09 & 0 \\
\hline $\begin{array}{l}\text { Total } \\
\text { SMR }\end{array}$ & 1 & $\begin{array}{r}0.05 \\
2000\end{array}$ & 2 & $\begin{array}{r}0.11 \\
1818\end{array}$ & 3 & $\begin{array}{r}0.19 \\
1578\end{array}$ & 6 & 0.31 & 1935 \\
\hline
\end{tabular}

$547-3264)$. The result was based on six cases of aplastic anemia versus 0.38 expected when all blood diseases were grouped together. The SMR for all neoplasms was significantly elevated (SMR 140, 95\% CI 109-181). Six cases of leukemia were observed versus the $1.5 \mathrm{ex}-$ pected (SMR 400, $95 \%$ CI 146-870).

Included in "other lymphatic and hematopoietic neoplasms" was a case of non-Hodgkin's lymphoma. Among the men the digestive tract neoplasms showed an SMR of $227(95 \%$ CI 147- 335), but only the stomach cancer excess was statistically significant (SMR 240, $95 \%$ CI 137-378).

Further analysis was carried out for the subcohort of men with "high" and "intermediate" levels of exposure. These subjects, at work in the period 19531964 and considered exposed to benzene, were classified into three groups by duration of exposure. All the cases of aplastic anemia and leukemia were observed in this subcohort.

The results for leukemia and aplastic anemia are shown in tables 3 and 4, subdivided by years of duration of exposure to benzene and by risk interval (time interval since first exposure), where 1 January 1953 was considered the date of first exposure for those who were employed before this date. Ten out of the 12 cases of aplastic anemia and leukemia occurred among the subjects with more than one year of employment in 1953-1964. The analysis by duration of exposure and time since first exposure did not show a pattern of increasing risk. Out of the 12 cases of leukemia and aplastic anemia, six were known before the study. If they are excluded, as Enterline suggests (10), an ex- cess of risk for the combined causes of death is still evident (observed 6, expected 1.58, SMR 380, $95 \%$ CI 138-826). In the subcohort considered unexposed to benzene, no case of aplastic anemia and leukemia occurred. In this subcohort the expected number of cases was 0.24 (SMR 0, $95 \%$ CI 0-1528).

The same analysis was carried out for stomach cancer. The SMR for stomach cancer was 425 (95\% CI 114-1089) for the unexposed workers versus an SMR of $212(95 \%$ CI 112-362) for the exposed subcohort.

Additional evidence available from a case-referent study carried out in the Province of Florence (11) allowed us to classify one case among the men as a "nasal adenocarcinoma." From clinical records two aplastic anemia deaths and one leukemia death were reclassified as acute erythromyelosis, considered as typically related to benzene exposure (2). The two more recent deaths from hemolymphopoietic tumors (one in 1979 and one in 1982) were due to non-Hodgkin's lymphoma and chronic lymphatic leukemia.

\section{Discussion}

The number of subjects lost to follow-up and the lack of information on some causes of death are limitations of this cohort study. The losses were due to incompleteness of the archives of the municipalities involved in the study.

The total mortality of the shoe worker cohort showed a deficit for both sexes. This frequently observed result is usually explained as being due to the 
"healthy worker effect." For the men the low SMR values for the major causal groups could also be partially explained by a lack of information on the cause of death for 22 deceased subjects.

Regional mortality rates are not available in Italy for the whole study period and therefore were not used as the reference.

\section{Aplastic anemia and leukemia}

This study confirms the strong temporal relationship between the occurrence of aplastic anemia and leukemia among shoe workers and the use of glues containing benzene.

Because of the expected number of cases of leukemia and aplastic anemia among the subjects beginning work after 1963, it is not possible to make a conclusive statement about the risk removal and its relationship to the possible effectiveness of the Italian regulation of 1963. Nevertheless, it is worthwhile to note that, out of the 14 cases (involving 12 men and 2 women) observed, none occurred among these subjects.

The absence of an excess of risk for leukemia and aplastic anemia among the women suggests either a differential susceptibility to benzene by sex or lower exposure levels for the women than the men. The power of this study and the information on exposure levels associated with specific jobs are not sufficient to clarify this issue. Risk did not increase clearly with duration of work, considered as an indicator of dose, and there was therefore no evidence of a dose-response relationship. This result could be due to the poor classification of the dose of exposure. A more-detailed job history description will be collected in view of the semiquantitative analysis of the exposure levels.

Another reason for the lack of relationship between risk and exposure could be that the exposure levels were high enough to produce substantial excesses even after shorter exposure intervals.

\section{Digestive tract neoplasins}

An association between stomach, rectal, and digestive tract cancers in the leather and shoe industry has been suggested in previous epidemiologic studies $(12,13$, 14). In the present study an elevated SMR for digestive tract cancers and, specifically, for stomach cancer was shown both for the whole cohort and separately for the two subcohorts (exposed and unexposed). In the Tuscan region, where the study was carried out, there is a higher mortality rate for stomach cancer than for the country as a whole. Furthermore the SMR for stomach cancer was higher in the unexposed subcohort than in the exposed group. Therefore the excess of stomach cancer does not seem to be related to benzene exposure. The information from the present study is not sufficient to evaluate whether or not the excess was due to occupational or related risk factors or simply due to an inappropriate choice of a reference population.

\section{Nasal cancer}

An excess of risk of nasal adenocarcinoma has been well described for shoe workers $(5,15)$. Only one case occurred among the members of our cohort. Two more cases of this rare tumor occurred among the workers registered in the plant in the period before 1950, and they are not included in this cohort.

\section{Concluding remarks}

These results concern the first true cohort study of shoe makers in Italy, a country in which a well-documented use of benzene occurred in shoe production and several case reports had suggested a consequent risk of hematopoietic diseases. Our results confirm the very high SMR values for leukemia and aplastic anemia among Italian shoe workers and are fully consistent with an association with exposure to benzene in glues. The effectiveness of the Italian law of 1963, which inhibited the use of glues with a benzene content of over $2 \%$, in preventing the occurrence of new cases of these diseases is also suggested by our results, but the conclusion cannot be conclusively evaluated.

\section{Acknowledgments}

We thank Professor C Maltoni and Dr F Carnevale for their advice and comments; Ms V Cacciarini helped with her accurate collection and preparation of the data. Ms G Lumachini typed the manuscript. Dr M Quinn's contribution was fundamental for the assessment of the exposure to benzene.

\section{References}

1. International Agency for Research on Cancer. Some industrial chemical and dyestuffs. Lyon: International Agency for Research on Cancer, 1982. (IARC: monographs on the evaluation of the carcinogenic risk of chemicals to humans; vol 29.)

2. Vigliani EC, Saita (i. Benzene and leukaemia. N Engl J Med 1964;271:872-6.

3. Aksoy M. Malignancy due to occupational exposure to benzene. Am J Ind Med 1985;7:395-402.

4. Maltoni C, Conti B, Cotti G, Balpoggi F. Experimental study on benzene carcinogenicity at the Bologna Institute of Oncology: current result and on-going research. Am J Ind Med 1985;7:415-46.

5. International Agency for Research on Cancer. Overall evaluations of carcinogenicity: an updating of IARC monographs volumes 1-42. Lyon: International Agency for Research on Cancer, 1987. (IARC monographs on the evaluation of the carcinogenic risk of chemicals to humans, supplement 7.)

6. International Agency for Research on Cancer. Wood leather and some associated industries. Lyon: International Agency for Research on Cancer, 1981. (IARC monographs on the evaluation of the carcinogenic risk of chemicals to humans; vol 25.)

7. World Health Organization. Manual of the international statistical classification of diseases, injuries and causes of death. Geneva: World Health Organization, 1967. (Eighth revision conference.)

8. Coleman M, Douglas A, Hermon C, Peto J. Cohort 
study analysis with a fortran computer program. Int $\mathrm{J}$ Epidemiol 1986;15:134- -7.

9. Breslow NE, Day NE. Statistical methods in cancer research; vol 11. Lyon: International Agency for Research on Cancer, 1988. (IARC scientific publication no 2.)

10. Cecchi F, Buiatti E, Kriebel D, Nastasi L, Santocci M. Adenocarcinoma of the nose and paranasal sinuses in shoemakers and wood workers in the Province of Florence, Italy, 1963/1977. Br J Ind Med 1980;3:222-5.

11. Enterline PE. Evaluating cancer clusters. Am J Hyg Assoc J 1985;46,3: B10-3.

12. Pippard EC, Acheson ED. The mortality of boot and shoe makers, with special reference to cancer. Scand J Work Environ Health 1985;11:249-55.
13. Berg JW, Howell MA. Occupational and bowel cancer. J Toxicol Environ Health 1975;1:75-89.

14. Garabrant DH. Cancer mortality among shoe and leather workers in Massachusetts. Am J Ind Med 1984; 5:303-14.

15. Merler E, Baldasseroni A, Laria R, et al. On the causal association between exposure to leather dust and nasal cancer: further evidence from a case control study. $\mathrm{Br}$ $\mathrm{J}$ Ind Med 1986;43,2:91-5.

Received for publication: 8 August 1989 